\title{
The Intrinsic Relationship Between Creative Culture Industry and City Brand Image Creation
}

\author{
Bo Fan \\ School of Energy Resources, China Univercsity of Geosciences (Beijing), Jinan, Shandong Province, China
}

Keywords:Budget management; Transit project; MVC model; Use case

\begin{abstract}
Due to the long-term complexity of cost-bearing methods for transportation project engineering, and in the process of construction, there are many problems, such as excess cost, excess material purchase, waste of resources and so on. Budget management can improve the management information and management content of traffic engineering projects, and help companies to achieve profits maximization and intensive utilization of resources. This paper aims to develop a budget management system, to promote the efficient budget management of engineering projects, and through data analysis method to better control the process of project construction, so as to guarantee the quality of the project and reduce the total cost.
\end{abstract}

\section{Introduction}

With the rapid development of market economy, companies with strong survivability tend to occupy the front end of the market configuration. The market law of the survival of the fittest has been applied to all sectors of the industry, also this law appears in the traffic engineering industry. With the introduction of road traffic management policy in China, the operating scale and management method of highway management is constantly changing. The market for traffic road projects has been further opened up, and a variety of private road projects have also intensified competition in the transportation industry, which gives higher management requirements to the system attached to the project management of the road project.

How to improve the comprehensive competitiveness of the transportation construction project, and improve the degree of trust and satisfaction of the masses, is the focus and development topic of the traffic management staff. This means that the entire traffic project management needs to follow a higher management system and constraints.

Therefore, transit project budget management comes into being. It is a system for the approval and management of road specification financial management, as well as an important means that can reasonably allocate and use operating costs.

\section{The internal logic between creative culture Industry and city brand construciton}

Cultural and creative industries mainly play the role in the moulding and dissemination of urban cultural brands from five aspects, and these five mechanisms of action are not separate from each other's role in urban cultural brands. The five mechanisms interact and restrict each other. The former industrial and urban development concepts have not only focused on the long-term pursuit of material values, instead, it began to pay attention to the way from hard power to soft power. Humanities development gets more attention, and the mechanism model of creative culture industry's promotion to city brans construction is shown in Fig.1. 


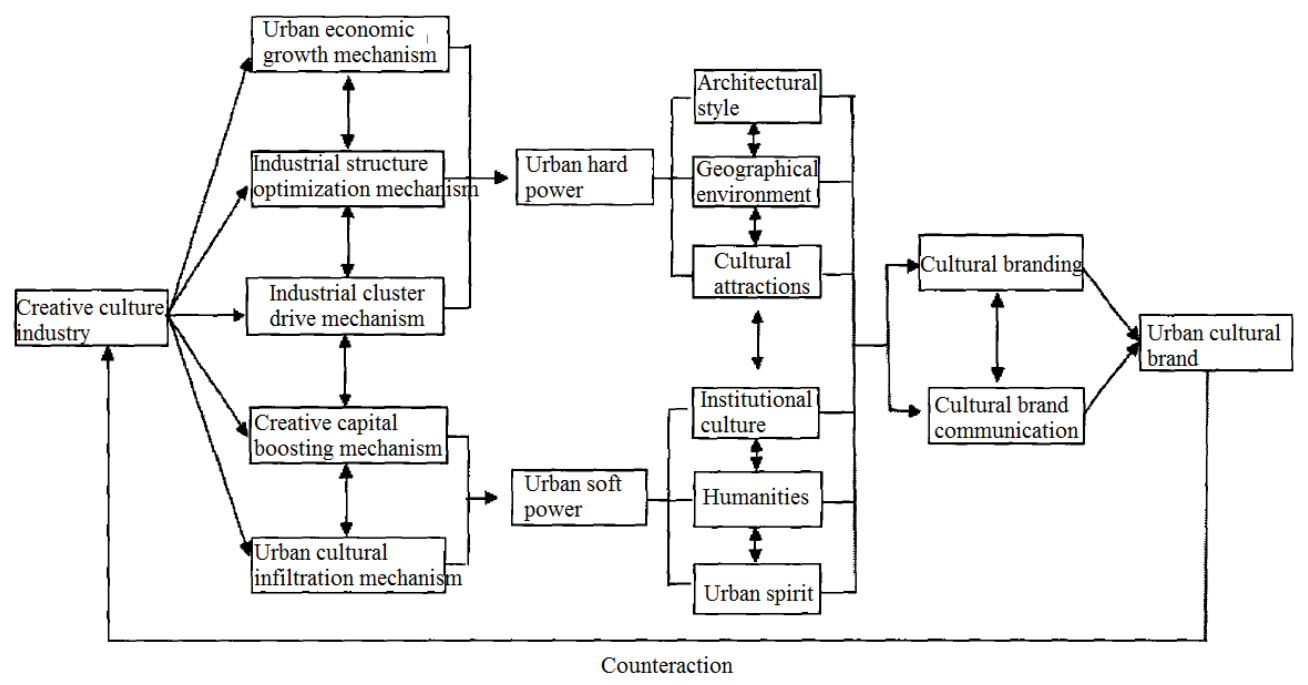

Fig.1 Mechanism model of creative culture industry’s promotion to city brans construction

\section{The Specific role of Creative Industry's Promotion to City Brands}

Creative industry influences urban hard power and soft power from five mechanisms, and it has an intrinsic and external role in the shaping and dissemination of urban cultural brands. We regard the role of the creative and cultural industry in the urban brand as an organic system, then the development of creative industries can have a positive and profound impact on the shaping and dissemination of urban cultural brands through these five subsystems, and the five mechanisms produce a synergy to fully enhance the competitiveness of urban brands.

\subsection{Urban economic growth mechanism}

\subsubsection{Brand strategy is based on urban economic strength}

Cultural economy and creative economy are special economic forms. Currently, the developed countries have taken the development of cultural and creative industries as an important pillar industry of the national economy. With the spread of economic and cultural globalization, the economic contribution of creative culture industry to the world economy is growing. The development of urban cultural brands, like commercial brands, requires strong operating capital as a basis for protection and a starting base. What's different from commercial brand building, cultural brands need clear cultural capital, rather than just economic capital.

The cities with relatively mature city brand culture in China are mostly provincial capital cities or a coastal city with strong economic strength, such as Hangzhou, Wuhan, Beijing, Shenzhen, etc. Overall speaking, an urban cultural industry infrastructure is inseparable from the investment of economic capital.

\subsubsection{Urban cultural brand communication is supported by economic investment}

Creative culture industry has a huge operational effect on economic development. It is not just a driving force for the urban economy as an emerging form of industry, more importantly, the cultural and creative elements derived from the industry have become powerful means and ways to promote economic growth.

Firstly, urban GDP growth allows cities to have the capital to invest more and more comprehensive resources in the shaping and dissemination of city brands. Secondly, because of the high added value and industry-driven attributes of creative culture industry, it can optimize and integrate peripheral non creative industries, and attracts more and more investors and high-end employment with huge profits, and thus speeds up the gathering and spreading speed of urban flow, 
capital flow, logistics and information flow. Meanwhile, the development of creative culture industry can obtain great economic and cultural value return from the communication of city brand.

\subsection{Industrial structure optimization mechanism}

\subsubsection{Industrial structure transformation strengthens urban culture mining}

The optimization and upgrading of industrial structure is the result of social and economic benefits generated by the reorganization and comprehensive coordination of all walks of life in cities. Traditional industries rely on direct transformation of tangible material resources and primary production factors, which is actually a mode of development that generates economic drivers through material consumption. In contrast, creative culture industry is dependent on the indirect injection of invisible creativity capital and spiritual resources into the various processes of cultural products and services, to drive the economic structure of the entire city with its nature of high added value, strong convergence, wide exposure, low energy consumption. There is a significant difference between the cultural creative industry and the traditional industry in terms of resource utilization. The former pays more attention to the integration and innovative use of advantageous urban resources, especially the capitalization, marketization, and commercialization development of urban culture, because it is more conducive to the continuation of the lifeblood of urban culture and the sustainable development of urban cultural brands.

\subsubsection{Industrial structure optimization promotes cultural branding}

Urban cultural brands are gradually formed as the social economy develops to a certain level. The essence of shaping urban cultural brands is the process to strengthen the urban soft power. To develop urban regional soft power, it must be supported by a group of creative cultural industries and industries that are closely related to cultural brands, such as publishing industry, tourism, show conventions, animation industry, etc. For example, the West Lake Creative Valley, Zhijiang Cultural and Creative Park, West Lake Digital Entertainment Industrial Park and Lok Fu Zhi Hui Garden have been built in Hangzhou have become the main platform to lead, inspire, and promote the optimal development of cultural and creative industries, and more than a hundred original animation companies are making Hangzhou an "city of animations."

It can be said that the strong industrial base and the industrialization of innovative products have provided a good basis for the development of urban cultural brands, in turn, scientific and rational urban industrial structure can provide inexhaustible motive force for the development of urban cultural brand and create a good development environment.

\subsubsection{Industrial structure upgrade promotes cultural brand communication}

Originally, the cultural and creative industry was separated from the machinery manufacturing design industry of the second industry. Integrated with tertiary industry, it creates a new type of industry with original creative ideas, scientific and technological research and development, etc. because of its high added value, low resource consumption, knowledge-intensive features, the development of creative cultural industries is less limited by land or material resources. Therefore, while giving added value to the product culture, creative culture industry can promote the transformation and upgrading of traditional industries to off-premise industries, and help to optimize the proportion of the internal structure of the tertiary industry itself, so that speed up the competitiveness of the industry.

\subsection{Industrial cluster drive mechanism}

\subsubsection{Industrial clusters are conducive to the formation of urban brands}

Through geographical proximity, creative culture industry cluster promotes a combination of many structural elements such as creative companies, R\&D institutions, mass media, and 
government service organizations into a regional symbiosis group, forming regional competitive advantage. Industrial clustering brings together a variety of information, talent, inventions, and market needs, and further amplify the benefits of production and innovation, which helps reduce transaction costs and the sharing and dissemination of information. Meanwhile, creative culture industry gives full play to the resource sharing effect. The sharing of market environment, space, infrastructure, and even technical information makes various resources more efficient.

The development mode that industrial cluster relying on the demonstration park and base has been a great success in practical use in China. The products they produce are easier to go to the outside, and even forming a famous regional brand. Regional brands are more competitive than a single brand, because it is an innovation shared by many enterprises. Once it's accepted by people and the market, it will produce a broader and more sustained brand effect, thus it is easier to form a good city brand.

\subsubsection{Industrial cluster is beneficial to the promotion of overall competitiveness}

In addition to bringing together a large number of enterprises, organizations, departments, institutions, etc. that have a division of labour cooperation relationship, the role of industrial clusters is to group together the resources involved in various production, reproduction, distribution, and distribution processes, to utilize the information sharing, innovation incentives, cooperation and win-win model to continuously improve the industrial economic scale of the cluster area.

Because a large number of related industries are concentrated in specific areas, the "survival of the fittest" competition mechanism within the industrial cluster will produce natural choices within the cluster, it will create a brand-new competitive advantage in the cluster that is more competitive than all single companies. This new cluster competitiveness will become a strong advantage for regional brands, to lay a competitive advantage for the moulding and spreading of the city brand.

\subsubsection{Industrial cluster is beneficial to brand innovation}

The "survival of the fittest" formed by the creative culture industry cluster will produce enormous innovation pressure, and this innovation pressure is mainly reflected in three aspects. Tthe first is to cultivate the ability of enterprise to learn and innovate, by forcing companies to continue to carry out technological reforms and organizational management optimization, so that accelerate product upgrading and catch up with changes in the new era of technological innovation. Second is to promote the transfer of knowledge and technology. Due to the need for division of labour, the highly related, highly specialized industries within the cluster is clustered in a region. In addition, the geographical specialities within the cluster make it easier and less costly for companies to learn new technologies, so the cost of corporate innovation is effectively controlled.

\subsection{Creative capital boosting mechanism}

\subsubsection{Cultural capital is the innovation of urban cultural brand management}

Cultural capital is mainly divided into two types: abstract attributes and specific attributes. Among them, the form of capital with abstract attributes is intangible cultural capital, as well as a kind of spiritual capital, including concepts, habits, beliefs, and values. Urban cultural capital needs timely maintenance, otherwise it will destroy to eliminate.

Cultural capital is the inheritance and propagation of historical accumulation, as well as a reflection of modern urban civilization. The building space, the humanistic landscape and the regional environment of a city are all dimensions of the form of cultural capitalization. Once the cultural capital is developed and put into use, it will convert into economic capital. The cultural capital is the structural basis for the effective development of a city in economic, social and political aspects, and is also the city's creative and cohesive container, as important elements of urban blessing and influence. 
In the city management, to carry out cultural capital transformation on all aspects of the city could help to shape and develop urban cultural brands, and thus improve the core competitiveness of cities.

\subsubsection{Human capital is the backing of cultural branding and communication}

The key element for developing cultural brands is the absorption of creative talents in cities. Creative talent play a key role in the excavation, shaping, packaging, promotion and management of urban culture, which provides intellectual and operational protection for the city's homogenous competition. In today's vigorous old city transformation campaign, many city signs increasingly converge, but only creative culture could make city features appear, and this requires a large number of talent backing. For example, Los Angeles has accumulated a large number of creative talents and film talents, so The Walt Disney Company and Laiqiao have monopolized the world theme entertainment market and the film market by virtue of this advantage.

\subsection{Urban cultural infiltration mechanism}

\subsubsection{Urban culture determines urban cultural brand positioning}

Urban culture is an effective city identifier. When entering a city, the first thing that comes into view is the layout of the apostles, the appearance of the building, the natural landscape, etc. in the city. These external images of a city will undoubtedly help the city to embody its value, however, if urban cultural infusion is abandoned in the city image construction, in the city image construction. Therefore, what really gives people long-term taste and attractiveness is the cultural value reflected in architecture, landscape, and humanities. When the city managers determines the direction and development strategy of the city brand, should dig deeper into the city's cultural personality and characteristics.

History and time have given each city different cultural personalities, which is either a national culture or a modern structure, or a composite feature, and urban cultural personality can only be fully highlighted through the construction of urban cultural brands.

\subsubsection{Urban brand communication is the process of cultural penetration}

Culture as a "heterogeneous" logo between cities and cities, it is an indispensable element for the construction of urban cultural brands. Urban cultural brand is at the same time a carrier for the continuation and development of the cultural lifeline. People are gradually learning about a city as they consume and enjoy the culture of the city and they also accepted and recognized the city's cultural brand in their subtle influence.

\section{References}

[1] Nováková H. Methodology of transportation project management[J]. Journal of Systems Integration, 2013, 4(3).

[2] Wysocki R K, Crane D B. Effective project management: how to plan, manage, and deliver projects on time and within budget[M]. John Wiley \& Sons, Inc. 1995.

[3] $\mathrm{Lu} \mathrm{H}$. Analysis on Problems at Construction Project Budget and the Solution[J]. Value Engineering, 2011.

[4] Xingwu L I, Liu X. On Platform Construction with Regard to Budget Management of Geological Survey Projects[J]. Natural Resource Economics of China, 2015.

[5] Wu B, Peng Y. The Design and Implementation of Budget Management System Based on ExtJS and ASP.NET[C]// International Conference on Information and Management Engineering. Springer, Berlin, Heidelberg, 2011:74-81. 
[6] Wen-An H U, Jun-Chuan J I, Jiao W B. Design and Implementation of B/S Mode Budget Management System[J]. Computer Systems \& Applications, 2010, 19(10):158-162.

[7] Moore A Y, Thomas M R, Diggdon A, et al. Budget management system and method[J]. 2014.

[8] Xue D M. On the problems and countermeasures of building comprehensive budget management system in new situation[J]. Technological Development of Enterprise, 2011.

[9] Ma S. A platform of comprehensive budget management system[C]// International Conference on Civil, Transportation and Environment. 2016. 